\section{Diaphragmatic rupture with inferior phrenic artery bleeding caused by cardiopulmonary resuscitation}

\author{
Umberto G. Rossi ${ }^{1,2}$, Anna Maria lerardi ${ }^{3}$, Maurizio Cariati ${ }^{2}$ \\ ${ }^{1}$ Interventional Radiology Unit, Department of Diagnostic Imaging, E.O. Galliera Hospital, Genova, Italy \\ ${ }^{2}$ Radiology and Interventional Radiology Unit, Advanced Technology Department of Diagnostic and Therapy, \\ ASST Santi Paolo and Carlo, San Carlo Borromeo Hospital, Milano, Italy \\ ${ }^{3}$ Radiology and Interventional Radiology Unit, Diagnostic and Interventional Radiology Department, ASST \\ Santi Paolo and Carlo, San Paolo Hospital, University of Milan, Milano, Italy
}

A 76-year-old hospitalized man developed acute ventricular fibrillation. The cardiology staff started cardiopulmonary resuscitation (CPR) with 30 chest compressions and two artificial ventilations, combined with automated external defibrillator use. The time to restore cardiac output was 25 minutes. Twelve hours later, he was extubated and started complaining of upper abdominal and back pain. Over this time, his hemoglobin level decreased from 13.4 to $8.7 \mathrm{mg} / \mathrm{dL}$. Multidetector computed tomography revealed a lesion in the right crus of the diaphragm and hemoperitoneum (Fig. 1A, B). Selective lower thoracic and upper abdominal digital subtraction angiography showed active bleeding from a branch vessel of the right inferior phrenic artery (Fig. 2A). Active bleeding was stopped by coaxial superselective catheterization of the right inferior phrenic artery (Fig. 2B). The postoperative course was uneventful; he was discharged on day 10. Follow-up performed 24 months after embolization demonstrated no complications.

Diaphragmatic lesions (varying from tearing of a muscle bundle to full-strength breakage) with inferior phrenic artery bleeding due to blunt trauma is a rare emergency event. ${ }^{1-3}$ Diaphragmatic rupture caused by CPR is even rarer. ${ }^{3}$ To our knowledge, this is the first case involving a diaphragmatic lesion and inferior phrenic artery rupture caused by CPR, leading to hemoperitoneum. This is a potentially life-threatening condition requiring prompt diagnosis and treatment. ${ }^{1,2,4}$ In selected cases involving active traumatic bleeding in thoraco-abdominal organs, transcatheter embolization techniques have been successfully used as the first-line treatment. ${ }^{5-7}$ In conclusion, the possibility of injury to abdominal organs, such as the diaphragm, must be considered while performing vigorous CPR.

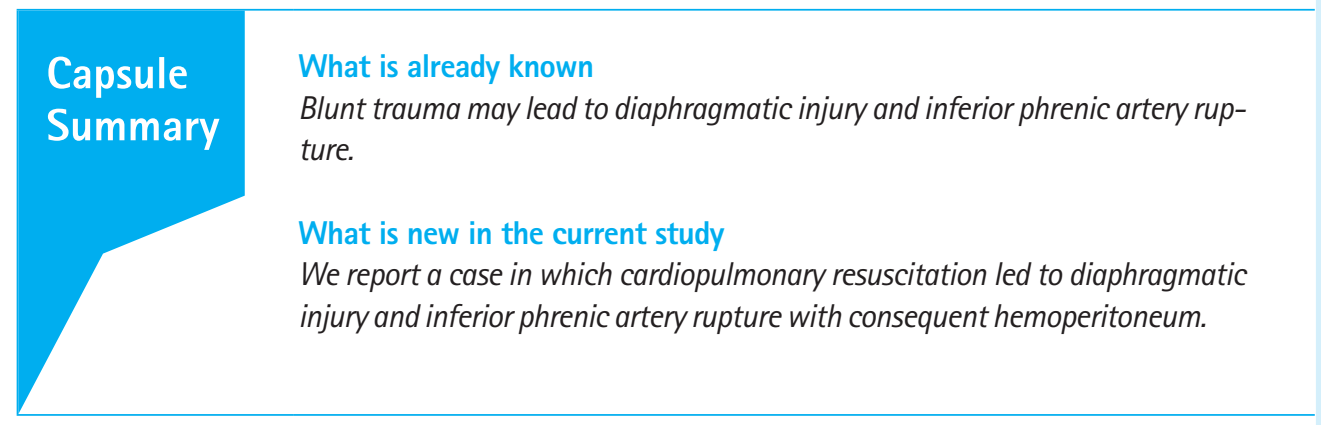

eISSN: $2383-4625$

Received: 18 May 2019

Revised: 2 July 2019

Accepted: 9 July 2019

Correspondence to: Umberto G. Rossi Interventional Radiology Unit, Department of Diagnostic Imaging, E.0. Galliera Hospital, Mura delle Cappuccine 14, Genova 16128, Italy E-mail: umberto.rossi@galliera.it ORCID

https://orcid.org/0000-0001-9785-4237

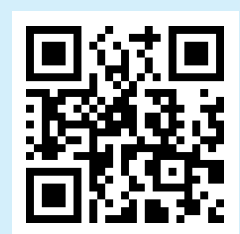

How to cite this article:

Rossi UG, lerardi AM, Cariati M. Diaphragmatic rupture with inferior phrenic artery bleeding caused by cardiopulmonary resuscitation. Clin Exp Emerg Med 2020;7(3):238-240. https://doi.org/10.15441/ ceem. 19.044

This is an Open Access article distributed under the terms of the Creative Commons Attribution Non-Commercial License (http:// creativecommons.org/licenses/by-nc/4.0/). 

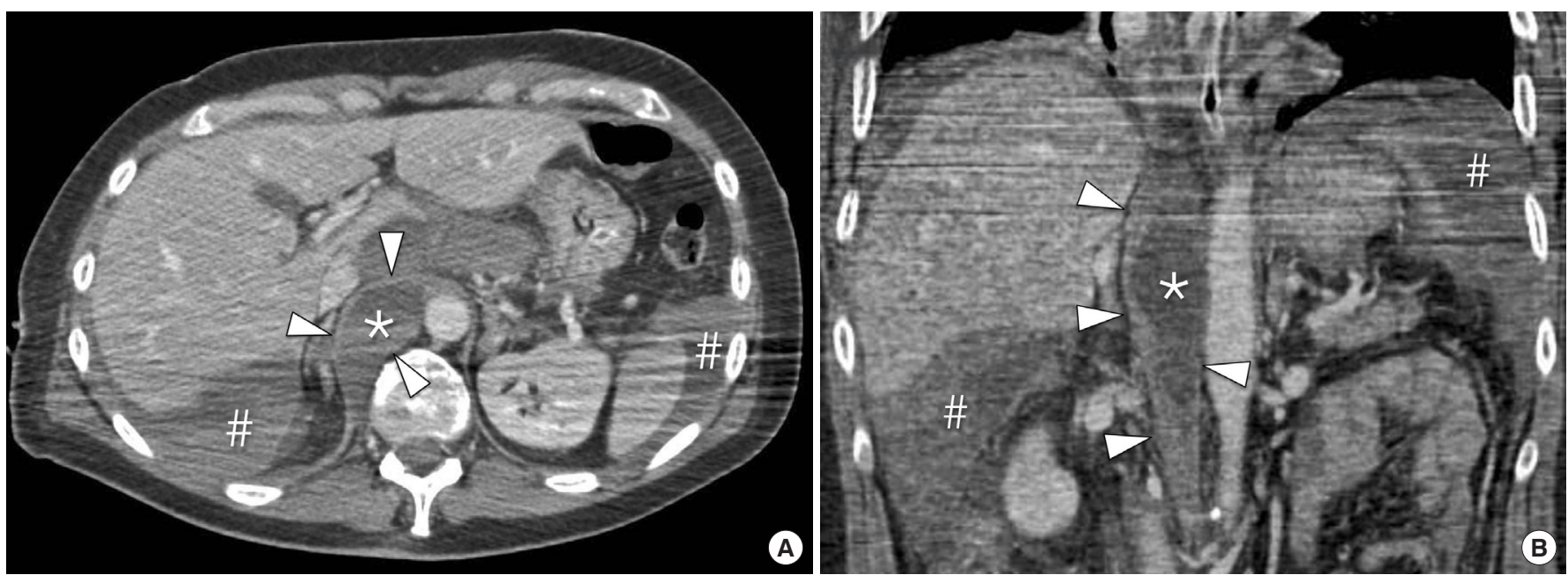

Fig. 1. (A) Axial and (B) coronal views of multidetector computed tomography showing a $7.3 \times 4.1-\mathrm{cm}$ inhomogeneous lesion $\left({ }^{*}\right)$ in the right crus of the diaphragm (arrowheads) with hemoperitoneum (\#).
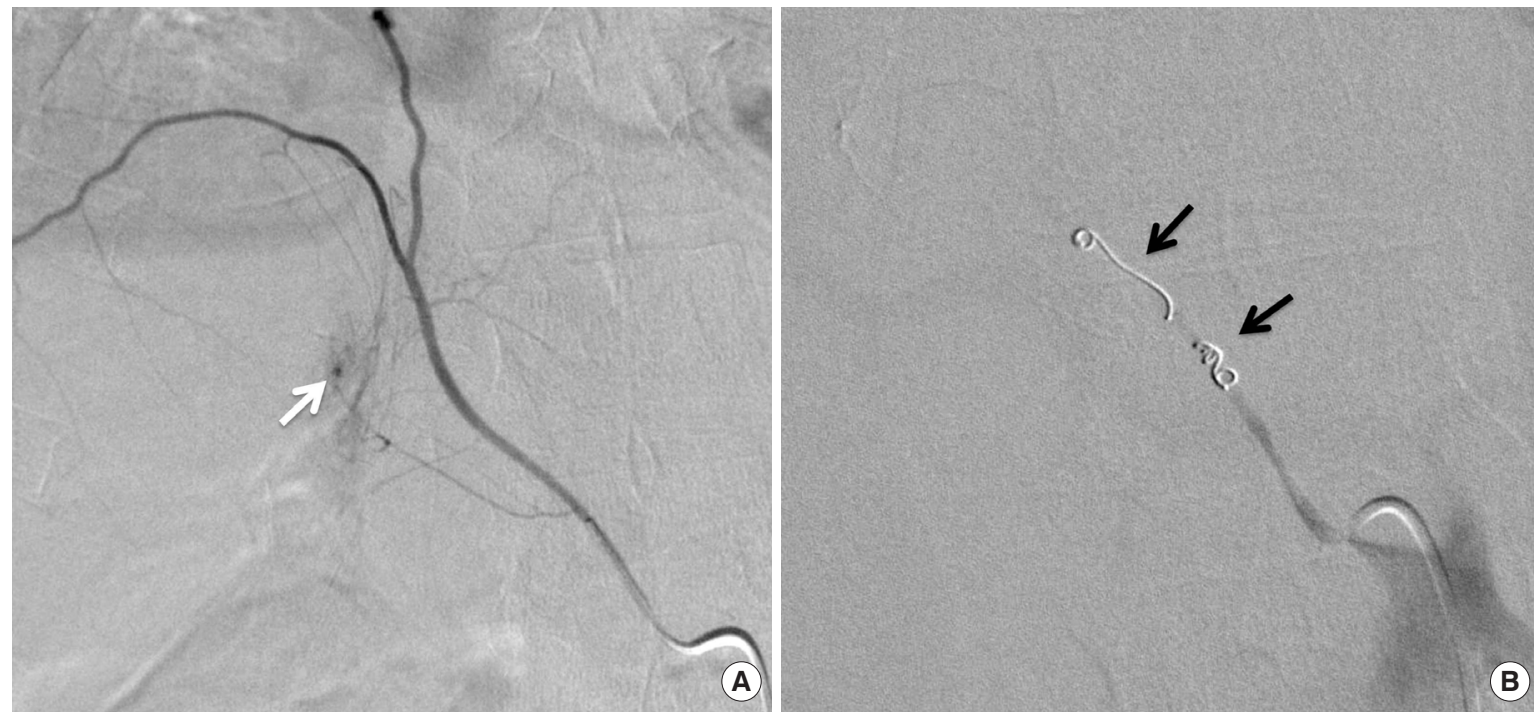

Fig. 2. (A) Selective digital subtraction angiography revealing active bleeding (white arrow) from a branch vessel of the right inferior phrenic artery. (B) Final selective angiography of the right inferior phrenic artery showing no signs of active bleeding after embolization with two 3-mm metallic microcoils (black arrows) using the endovascular "isolation technique."

\section{CONFLICT OF INTEREST}

No potential conflict of interest relevant to this article was reported.

\section{REFERENCES}

1. Kearney PA, Rouhana SW, Burney RE. Blunt rupture of the diaphragm: mechanism, diagnosis, and treatment. Ann Emerg Med 1989;18:1326-30.
2. Lee JW, Kim S, Kim CW, Kim KH, Jeon TY. Massive hemoperitoneum due to ruptured inferior phrenic artery pseudoaneurysm after blunt trauma. Emerg Radiol 2006;13:147-9.

3. Sabzi F, Faraji R. Diaphragmatic rupture and hernia after cardiopulmonary resuscitation. Tanaffos 2017;16:170-2.

4. Kim SK, Jung JH, Lee JH, et al. The difference of Use of $\mathrm{CT}$ in the general versus pediatric emergency departments for adolescent patients in the same tertiary hospital. Clin Exp Emerg Med 2019;6:19-24.

5. Rossi UG, Camisassi N, Pinna F, Rollandi GA. Spontaneous he- 
patic haemangioma rupture and hemoperitoneum: a double problem with a single stage interventional radiology solution. Clin Exp Emerg Med 2019;6:169-72.

6. Martin JG, Shah J, Robinson C, Dariushnia S. Evaluation and management of blunt solid organ trauma. Tech Vasc Interv
Radiol 2017;20:230-6.

7. Rossi UG, Seitun S, Ferro C. Endovascular embolization of a third jejunal artery aneurysm: isolation technique using the Amplatzer vascular plug 4. Catheter Cardiovasc Interv 2013; 81:1049-52. 